\section{Focused ultrasound and prostate cancer}

\author{
Sung Kyu Hong, Hakmin Lee
}

Department of Urology, Seoul National University Bundang Hospital, Seongnam, Korea

Focused ultrasound (FUS) has been utilized for the treatment of localized prostate cancer. Initially, FUS was performed as a whole-gland treatment comparable to radical prostatectomy or radiation therapy. However, after overall downward stage migration due to health screening programs involving prostate-specific antigen testing, as well as advances in conservative or observative strategies such as active surveillance, FUS has evolved from a whole-gland treatment to a focal treatment. This new treatment technique aims to ablate tumors while preserving the normal prostate tissue, thereby ensuring better preservation of urinary and erectile function. In this article, we review the mechanism and clinical outcomes of the FUS procedure.

Keywords: Focused ultrasound; High intensity focused ultrasound; Prostatic neoplasms

\section{Introduction}

Focused ultrasound (FUS), also called high-intensity focused ultrasound, has been used for more than 70 years after the first theoretical demonstration by Lynn et al. in the 1940s [1]. They reported that FUS can cause tissue destruction with no damage to the overlying and/or surrounding tissue. The first clinical application of FUS for the treatment of prostate cancer (PCa) was recorded in France following the development of a FUS device in 1999 by a French company (Ablatherm, EDAP TMS, Vaulx-en-Velin, France) [2]. This device was designed to be inserted into the patient's rectum via the anus. It had two separate ultrasound transducers in a single probe, one for imaging and one for treatment. In France, FUS was approved for the treatment of localized PCa in 2003 and gained national reimbursement from the French Ministry of Health in 2014. Another company (SonaCare Medical LLC, Charlotte, NC, USA) also released its prototype of a transrectal FUS machine in 2004. Both companies gained approval from the Food and Drug Administration of the United States as devices for the destruction of prostate tissue. Thus, with regard to the treatment of PCa, FUS is not a new technology per se [3]. In the present article, we highlight the advantages and disadvantages of the clinical application of FUS in the treatment of PCa.

\section{Drawbacks of Conventional Definitive Treatments and Active Surveillance}

Following the first perineal radical prostatectomy, conducted by Theodor Billroth in 1867, radical prostatectomy was the most frequently used treatment modality for PCa [4]. However, radical prostatectomy results in a severe decrease in the quality of life of many patients due to postoperative incontinence and erectile dysfunction, even when performed with the most advanced and up-todate surgical techniques $[5,6]$. Serum prostate-specific antigen (PSA) screening has led to the notable

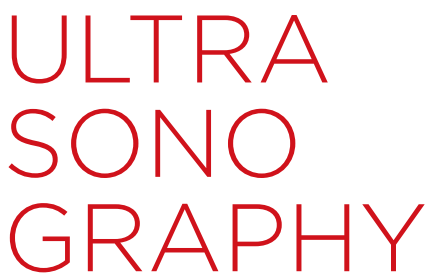

\section{REVIEW ARTICLE}

https://doi.org/10.14366/usg.20100 pISSN: 2288-5919 • elSSN: 2288-5943

Ultrasonography 2021;40:191-196

Received: June 30, 2020

Revised: August 31, 2020

Accepted: September 1, 2020

Correspondence to:

Hakmin Lee, MD, Department of Urology, Seoul National University Bundang Hospital, 82 Gumi-ro 173 beon-gil, Bundang-gu, Seongnam 13620, Korea

Tel. $+82-31-787-7343$

Fax. +82-31-787-4057

E-mail:65828@snubh.org

This is an Open Access article distributed under the terms of the Creative Commons Attribution NonCommercial License (http://creativecommons.org licenses/by-nc/4.0/) which permits unrestricted noncommercial use, distribution, and reproduction in any medium, provided the original work is properly cited.

Copyright (C) 2021 Korean Society of Ultrasound in Medicine (KSUM)

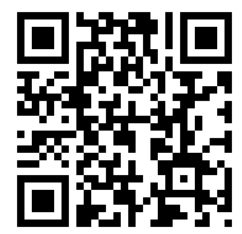

How to cite this article:

Hong SK, Lee H. Focused ultrasound and prostate cancer. Ultrasonography. 2021 Apr;40(2):191-196. 
downward stage migration of PCa during the last several decades [7]. Understandably, concerns about the overtreatment of patients with low cellular grade and small tumor volume have been raised with regard to the relatively slow natural progression of $\mathrm{PCa}$ [8]. Hence, the concept of active surveillance was established, which aims to defer definitive treatment when no clinical evidence of disease progression exists. Recent data from Klotz et al. [9] on longterm survival outcomes using active surveillance showed that active surveillance is safe and effective, with 10-year and 15-year cancerspecific survival rates of $98.1 \%$ and $94.3 \%$, respectively. However, patients under active surveillance inevitably need to undergo repeated prostate biopsies because no definitive clinical tool can accurately identify the progression of disease without tissue biopsy. As prostate biopsy causes considerable discomfort during the procedure and can even lead to lethal complications such as septic shock, active surveillance also has major drawbacks.

\section{Mechanism of FUS}

The current FUS system utilizes both thermal and non-thermal effects. The high concentration of ultrasound energy elevates the tissue temperature to $80^{\circ} \mathrm{C}-100^{\circ} \mathrm{C}$ and consequently causes direct tissue damage, ultimately resulting in coagulation necrosis at the target lesion $[3,10]$. The non-thermal effects are related to the formation of boiling microbubbles and the irreversible mechanical damage to the cellular membrane. Because the device is designed to concentrate the ultrasound waves, tissue damage by FUS is usually only achieved in a very small, confined ablation area. This small ablation area (usually referred to as the focal point), which can typically be ablated by a single concentrated ultrasound beam, is usually fixed in size and shape according to the predetermined settings of the FUS machine. When the procedure is performed correctly, tissue damage only occurs at this focal point, and the tissue surrounding this point is preserved. Currently-available commercial FUS machines have different focal point sizes; for example, the Focal One device manufactured by EDAP TMS has a focal point of $1.7 \mathrm{~mm} \times 1.7 \mathrm{~mm} \times 5 \mathrm{~mm}$, and the SonaCare Sonablate device has a focal point of $3 \mathrm{~mm} \times 3 \mathrm{~mm} \times 12 \mathrm{~mm}$. To ablate a zone or area (e.g., hemi- or whole-gland ablation), these FUS machines should be used to perform continuous ablations at numerous focal points, which are stacked side by side (Fig. 1A). To stack the focal points accurately, the machines need accurate imaging tracking and probe control systems to reduce the possibility of empty spots and missing lesions. However, this process of focal point stacking may theoretically have some margin of error (Fig. 1B). First, the prostate is moved during the procedure by continuous peristalsis in the rectum and indirect movement from other organs. Second, probe rotation and/or movement between each ablation can cause targeting errors. More importantly, the ablation itself causes significant tissue swelling during the procedure; thus, some degree of discordance is always present between the initial treatment plan and the actual ablation, and constant corrections are required. These errors may be associated with treatment failure or undertreatment following FUS; nevertheless, it is impossible to notice these missed lesions during conventional FUS using ultrasound imaging because monitoring tissue changes is nearly impossible using those devices. The more recently-developed technique of magnetic resonance imaging (MRI)-guided FUS now offers thermometry software that enables real-time temperature feedback during ablation and may be associated with a higher ablation success rate than previous FUS devices [11]. However, it remains to be elucidated whether these socalled MRI-guided in-bore FUS devices have significantly superior outcomes in terms of treatment success. In addition to conventional FUS devices that operate with a transrectal approach, transurethral

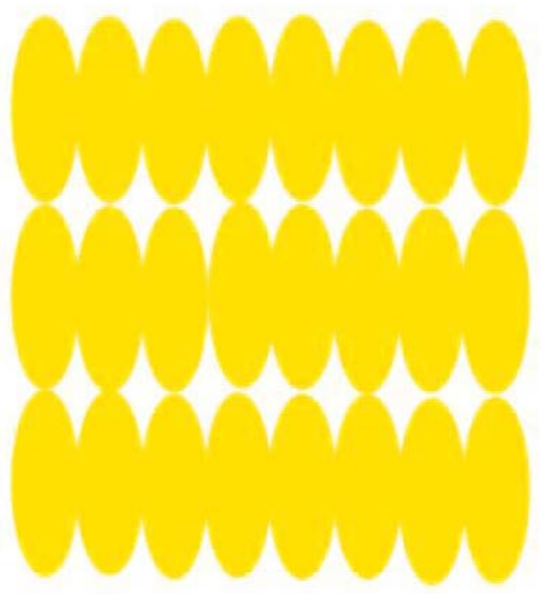

A

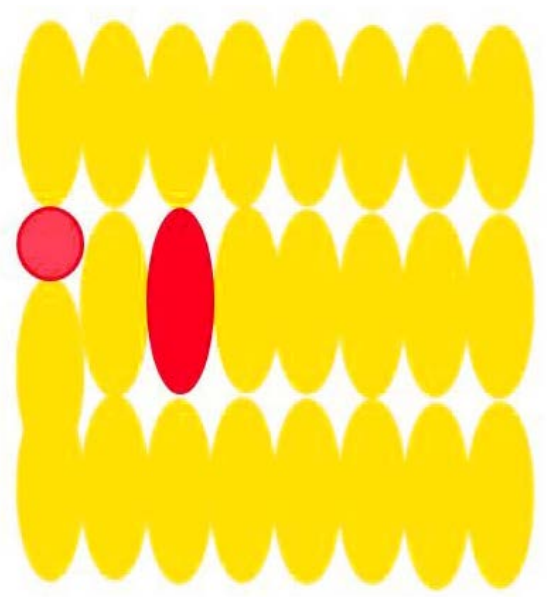

B
Fig. 1. Some possibility of empty spots and missing lesions always exists during ablation.

A. The yellow circles indicate the well-aligned theoretical focal points in the preoperative ablation plan. B. Errors and missing lesions between the ablated points are possible due to prostate movement and/or swelling. The red circle indicates a theoretical missing spot during ablation. 
FUS devices have been designed to reduce rectal complications and to improve the capacity to ablate the anterior prostate [12].

\section{Possible Benefits of FUS}

Although current FUS devices are not flawless, they offer several clinical benefits for PCa patients. First, FUS is a noninvasive procedure, as no puncturing of the skin or mucosa is involved. Second, FUS can be personalized according to the patient's disease profile. Thus, clinicians can modify the shape of the ablation zone freely according to the size and location of the tumor. However, many patients have tumors that are not visible on conventional imaging; therefore, not every patient can be treated focally. Nevertheless, patients with visible PCa can be treated either partially or focally using FUS; this provides far greater preservation of erectile and urinary function, resulting in improved quality of life. Third, FUS can also be a good option for patients with remnants of PCa in the prostate after primary radiotherapy. However, it should be noted that previous studies have shown relatively higher rates of urinary (ranging from 32\% to 36\%) and rectal complications (ranging from $4 \%$ to $16 \%$ ) among FUS patients on salvage therapy than among primary FUS patients [13-15].

\section{Clinical Outcomes after FUS}

Although various types of FUS can be performed according to the shape of the ablation zone, current techniques can be roughly categorized into whole-gland ablation, hemi-gland ablation, and focal ablation. The oncological and functional outcomes should be evaluated separately according to the type of ablation. In the present study, we discuss whole-gland ablation and hemi-gland ablation only, because sufficient data are unavailable regarding pure focal ablation.

\section{Whole-Gland Ablation}

Initially, most FUS procedures were performed as whole-gland ablations (Table 1) [16-19]. Thuroff and Chaussy [16] analyzed 704 patients who were treated with FUS after a median follow-up period of 5.3 years. The PSA nadir was reached at a mean of 2.1 months after FUS in that study. The 10-year cancer-specific survival rate was $99 \%$, and the metastasis-free survival rate was $95 \%$. The 10 -year rate of salvage therapy was $2 \%$ in the low-risk group and $27 \%-36 \%$ in the intermediate- and high-risk groups. The overall complication rate was $16 \%$ and tended to decrease as the surgeon's experience increased. Another study, conducted by Ganzer et al. [17], summarized the data of 538 patients after whole-gland FUS, with a median follow-up period of 8.1 years. In that study, the PSA nadir was reached at a mean of 5 months after FUS, and the metastasis rate was $0.4 \%$ in the low-risk group, $5.7 \%$ in the intermediate group, and $15.4 \%$ in the high-risk group. The cancerspecific mortality rate was $0 \%$ in the low-risk group, $3.8 \%$ in the intermediate group, and $11 \%$ in the high-risk group. The 10 -year biochemical recurrence rate was $29 \%$ in the low-risk group, $37 \%$ in the intermediate-risk group, and $68 \%$ in the high-risk group. Crouzet et al. [18] also analyzed a large database of 1,002 patients who were treated using whole-gland ablation between 1997 and 2009, with a median follow-up duration of 6.4 years. The 10-year overall survival rate was $80 \%$, and the cancer-specific survival rate was 97\% (low-risk, 99\%; intermediate-risk, 98\%; high-risk, $92 \%$ ). The 10 -year metastasis-free survival rates were $94 \%$ overall

Table 1. Previous publications on oncological and functional outcomes following whole-gland focused ultrasound

\begin{tabular}{|c|c|c|c|c|c|}
\hline Authors/study period/device & No. of subjects & $\begin{array}{l}\text { Follow-up period, } \\
\text { mean (range, y) }\end{array}$ & $\begin{array}{c}\text { Cancer-specific survival } \\
\text { rate(s) }(\%)\end{array}$ & $\begin{array}{c}\text { Metastasis-free survival } \\
\text { rate(s) (\%) }\end{array}$ & $\begin{array}{c}\text { Salvage treatment-free } \\
\text { survival rate(s) (\%) }\end{array}$ \\
\hline $\begin{array}{l}\text { Ganzer et al., 1997-2009, } \\
\text { Ablatherm [17] }\end{array}$ & 538 & $8.1(2.1-14)$ & $\begin{array}{l}\text { Overall: } 86.7 \\
\text { Low risk: } 100 \\
\text { Intermediate risk: } 96.2 \\
\text { High risk: } 89\end{array}$ & $\begin{array}{l}\text { Low risk: } 99.6 \\
\text { Intermediate risk: } 94.3 \\
\text { High risk: } 84.6\end{array}$ & $\begin{array}{l}\text { Overall: } 82 \\
\text { Low risk: } 99.6 \\
\text { Intermediate risk: } 94.3 \\
\text { High risk: } 84.6\end{array}$ \\
\hline $\begin{array}{l}\text { Crouzet et al., 1997-2009, } \\
\text { Ablatherm [18] }\end{array}$ & 1,002 & $6.4(0.2-13.9)$ & $\begin{array}{l}\text { At } 10 \text { years } \\
\text { Overall: } 97 \\
\text { Low risk: } 99 \\
\text { Intermediate risk: } 98 \\
\text { High risk: } 92\end{array}$ & $\begin{array}{l}\text { At } 10 \text { years } \\
\text { Overall: } 94 \\
\text { Low risk: } 99 \\
\text { Intermediate risk: } 95 \\
\text { High risk: } 86\end{array}$ & $\begin{array}{l}\text { At } 5 \text { years } \\
\text { Low risk: } 81 \\
\text { Intermediate risk: } 68 \\
\text { High risk: } 66\end{array}$ \\
\hline
\end{tabular}


and $99 \%, 95 \%$, and $86 \%$ in the low-, intermediate-, and highrisk groups, respectively. Incontinence of grade $\geq 2$ was observed in 50 patients (5\%), and grade 1 incontinence was observed in 187 patients (18.7\%).

\section{Hemi-gland Ablation}

To provide better functional outcomes, FUS procedures have evolved into focal treatments (Table 2, Fig. 2) [20-22]. Rischmann et al. performed hemi-gland ablation in 111 patients with the following inclusion criteria: unilateral disease, Gleason score $\leq 7(3+4)$, and clinical stage $\leq T 2$ [20]. They performed follow-up biopsy 1 year after FUS, and no tumor was observed in the treated lobe in $86 \%$ of patients. Erectile function had normalized to the preoperative status in $78 \%$ of patients, and incontinence was only observed in $3 \%$ of all patients (all of whom exhibited grade 1 incontinence). Feijoo et al. [21] performed a prospective study after FUS in 71 patients with unilateral disease. Follow-up biopsy revealed that $25.4 \%$ of the total patients had remnant or recurrent tumors $(14.9 \%$ in the

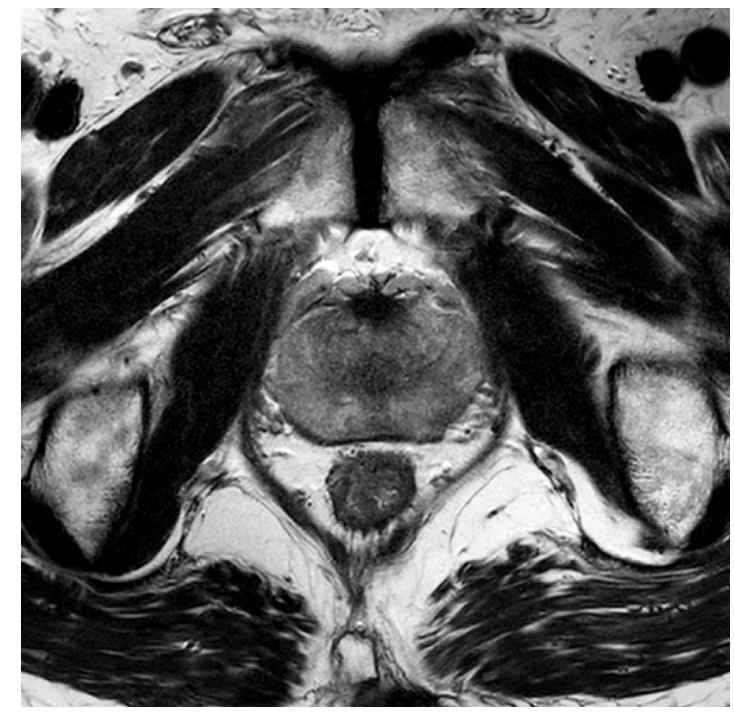

A

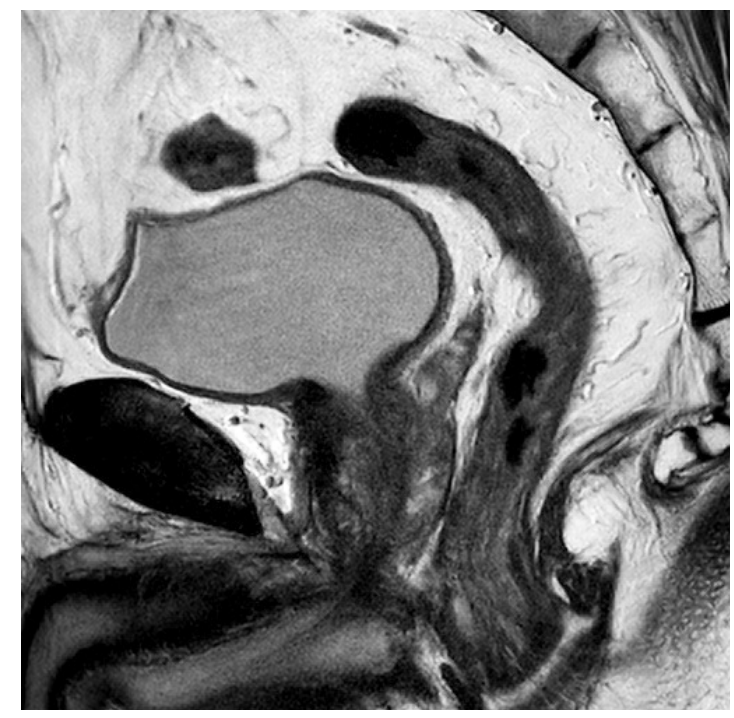

C

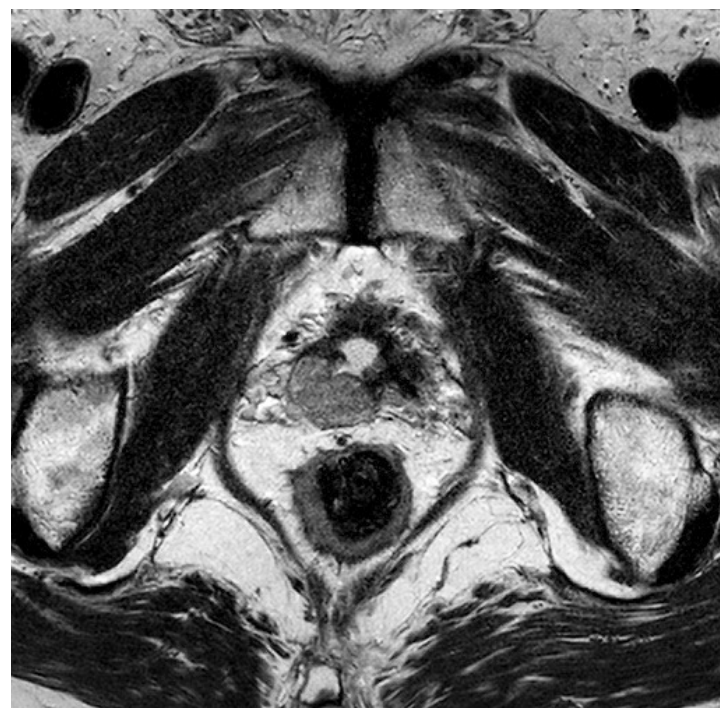

B

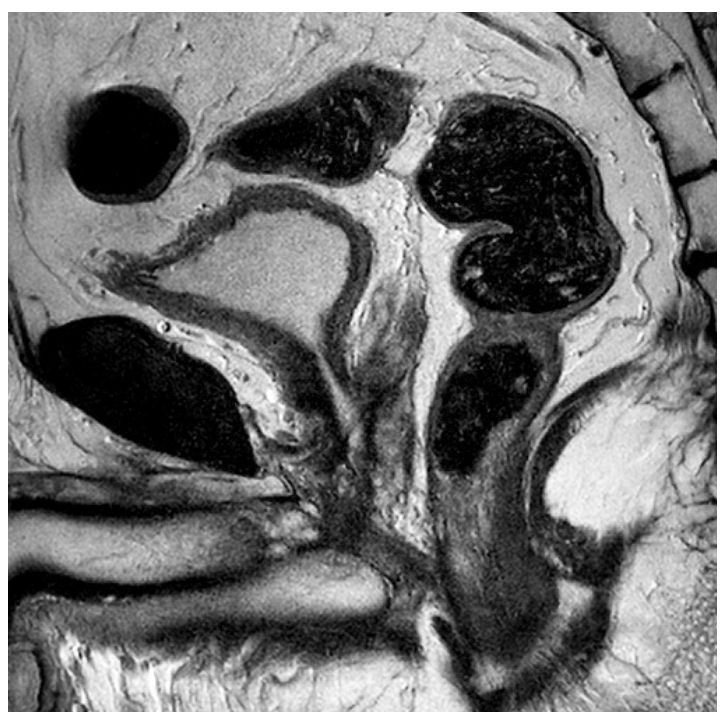

D

Fig. 2. Magnetic resonance images from a 73-year-old man with prostate cancer who was treated with left hemi-ablation using focused ultrasound with transurethral prostatectomy.

A, C. The prostate size was estimated as 44 cc based on a preoperative T2-weighted image (A, axial image on the mid-prostate; $C$, sagittal image at the midline). B, D. At 6 months after focused ultrasound ablation (left hemi-ablation), the size of the remaining prostate was estimated as 6-7 mL with negative prostate biopsies in both lobes (B, axial image; D, sagittal image). 
Table 2. Previous publications on oncological and functional outcomes following hemi-ablation focused ultrasound

\begin{tabular}{|c|c|c|c|c|c|}
\hline Authors/study period/device & No. of subjects & Follow-up period (mo) & Infield positive rate (\%) & Outfield positive rate (\%) & Rate of csPCa (\%) \\
\hline $\begin{array}{l}\text { Rischmann et al., 2009-2015, } \\
\text { Ablatherm [20] }\end{array}$ & 111 & Mean, 30.4 & $\begin{array}{c}14 \\
\text { (bilateral lobe positive, 2) }\end{array}$ & 19 & $\begin{array}{l}\text { Infield: } 5 \\
\text { Outfield: } 7\end{array}$ \\
\hline $\begin{array}{l}\text { Feijoo et al., 2009-2013, } \\
\text { Ablatherm [21] }\end{array}$ & 71 & Median, 12 (IQR, 6-50) & $\begin{array}{c}16.4 \\
\text { (bilateral lobe positive, 1.5) }\end{array}$ & 9 & Not reported \\
\hline $\begin{array}{l}\text { Ganzer et al., 2013-2016, } \\
\text { Ablatherm/Focal One [22] }\end{array}$ & 51 & Mean, 17.4 & 26.5 & 34.7 & $\begin{array}{l}\text { Infield: } 8.2 \\
\text { Outfield: } 1\end{array}$ \\
\hline
\end{tabular}

csPCa, clinically significant prostate cancer; infield, area treated with FUS; outfield, area untreated with FUS; IQR, interquartile range.

treated area, $9 \%$ in the untreated area, and $1.5 \%$ in the bilateral lobes). Another study by Ganzer et al. [22] was a prospective study with 54 participants. Follow-up biopsy was performed at 1 -year postoperation, and they found that $26.5 \%$ of patients had tumor remnants in the treated lobe, while $28.6 \%$ of patients had contralateral disease in the untreated lobe that was not identified in the initial biopsy before FUS.

\section{Conclusion}

FUS is a noninvasive and relatively painless treatment compared to conventional surgical treatment and radiation therapy. Moreover, it can preserve erectile and urinary function, which is essential for maintaining patients' quality of life. However, FUS has several limitations. First, previous studies of hemi-ablation have shown that $15 \%-26.5 \%$ of patients had persistent tumors in the treated lobe, which should be regarded as treatment failure. Thus, the overall oncological outcomes may be inferior to those of radical treatments, and this possibility of undertreatment should be well-recognized by both clinicians and patients. Second, focal therapy can be more beneficial to the patients' functional preservation than wholegland therapy. However, $10 \%-30 \%$ of patients have tumors that are missing from initial biopsies and imaging studies. Therefore, it is quite difficult to determine the optimal focal therapy for patients. Hence, clinicians should counsel patients about the possible risk of progression of undetected PCa after focal FUS. Third, prostate and mucosal tissues tend to contract after FUS, and approximately $10 \%-20 \%$ of patients may need another procedure due to urethral stricture or stenosis following FUS. Fourth, PSA kinetic profiles and MRI are not reliable follow-up tools for the identification of FUSrefractory disease. Hence, follow-up biopsy is needed after focal or hemi-gland ablation, which can cause discomfort and severe complications such as sepsis. Nevertheless, FUS can be beneficial to some patients with low-volume and low-grade disease while preserving urinary and erectile functions, which can have a considerable impact on quality of life. We believe that the selection of suitable candidates for treatment with FUS is of great importance with regard to oncological outcomes. Therefore, further efforts in the development of imaging tools to accurately identify PCa and the selection criteria for patients are needed.

ORCID: Sung Kyu Hong: https://orcid.org/0000-0002-8344-6774; Hakmin Lee: https://orcid.org/0000-0002-1247-9958

\section{Author Contributions}

Conceptualization: Lee $\mathrm{H}$, Hong SK. Drafting of the manuscript: Lee $\mathrm{H}$, Hong SK. Critical revision of the manuscript: Lee H. Approval of the final version of the manuscript: all authors

\section{Conflict of Interest}

No potential conflict of interest relevant to this article was reported.

\section{References}

1. Lynn JG, Zwemer RL, Chick AJ, Miller AE. A new method for the generation and use of focused ultrasound in experimental biology. J Gen Physiol 1942;26:179-193.

2. Gelet A, Chapelon JY, Bouvier R, Pangaud C, Lasne Y. Local control of prostate cancer by transrectal high intensity focused ultrasound therapy: preliminary results. J Urol 1999;161:156-162.

3. Maloney $\mathrm{E}$, Hwang JH. Emerging HIFU applications in cancer therapy. Int J Hyperthermia 2015;31:302-309.

4. Billroth T. Surgical experience. Zurich 1860-67. Arch Klin Chir 1869;10:548-549.

5. Kirschner-Hermanns R, Jakse G. Quality of life following radical prostatectomy. Crit Rev Oncol Hematol 2002;43:141-151.

6. Lardas M, Liew M, van den Bergh RC, De Santis M, Bellmunt J, Van den Broeck $T$, et al. Quality of life outcomes after primary treatment for clinically localised prostate cancer: a systematic review. Eur Urol 2017;72:869-885.

7. Noldus J, Graefen M, Haese A, Henke RP, Hammerer P, Huland H. Stage migration in clinically localized prostate cancer. Eur Urol 2000;38:74-78.

8. Kinsella N, Helleman J, Bruinsma S, Carlsson S, Cahill D, Brown C, et al. Active surveillance for prostate cancer: a systematic review of 
contemporary worldwide practices. Transl Androl Urol 2018;7:8397.

9. Klotz L, Vesprini D, Sethukavalan P, Jethava V, Zhang L, Jain $S$, et al. Long-term follow-up of a large active surveillance cohort of patients with prostate cancer. J Clin Oncol 2015;33:272-277.

10. Alkhorayef M, Mahmoud MZ, Alzimami KS, Sulieman A, Fagiri MA. High-intensity focused ultrasound (HIFU) in localized prostate cancer treatment. Pol J Radiol 2015;80:131-141.

11. Kuroda K. MR techniques for guiding high-intensity focused ultrasound (HIFU) treatments. J Magn Reson Imaging 2018;47:316331.

12. Burtnyk M, Hill T, Cadieux-Pitre H, Welch I. Magnetic resonance image guided transurethral ultrasound prostate ablation: a preclinical safety and feasibility study with 28-day followup. J Urol 2015;193:1669-1675.

13. Dason S, Wong NC, Allard CB, Hoogenes J, Orovan W, Shayegan B. High-intensity focused ultrasound (HIFU) as salvage therapy for radio-recurrent prostate cancer: predictors of disease response. Int Braz J Urol 2018;44:248-257.

14. Ahmed HU, Cathcart P, McCartan N, Kirkham A, Allen C, Freeman $A$, et al. Focal salvage therapy for localized prostate cancer recurrence after external beam radiotherapy: a pilot study. Cancer 2012;118:4148-4155.

15. Crouzet S, Murat FJ, Pommier P, Poissonnier L, Pasticier G, Rouviere 0 , et al. Locally recurrent prostate cancer after initial radiation therapy: early salvage high-intensity focused ultrasound improves oncologic outcomes. Radiother Oncol 2012;105:198-202.

16. Thuroff S, Chaussy C. Evolution and outcomes of $3 \mathrm{MHz}$ high intensity focused ultrasound therapy for localized prostate cancer during 15 years. J Urol 2013;190:702-710.

17. Ganzer R, Fritsche HM, Brandtner A, Brundl J, Koch D, Wieland WF, et al. Fourteen-year oncological and functional outcomes of highintensity focused ultrasound in localized prostate cancer. BJU Int 2013;112:322-329.

18. Crouzet S, Chapelon JY, Rouviere O, Mege-Lechevallier F, Colombel $\mathrm{M}$, Tonoli-Catez $\mathrm{H}$, et al. Whole-gland ablation of localized prostate cancer with high-intensity focused ultrasound: oncologic outcomes and morbidity in 1002 patients. Eur Urol 2014;65:907-914.

19. Uchida T, Tomonaga T, Kim H, Nakano M, Shoji S, Nagata Y, et al. Improved outcomes with advancements in high intensity focused ultrasound devices for the treatment of localized prostate cancer. J Urol 2015;193:103-110.

20. Rischmann P, Gelet A, Riche B, Villers A, Pasticier G, Bondil P, et al. Focal high intensity focused ultrasound of unilateral localized prostate cancer: a prospective multicentric hemiablation study of 111 patients. Eur Urol 2017;71:267-273.

21. Feijoo ER, Sivaraman A, Barret E, Sanchez-Salas R, Galiano M, Rozet $F$, et al. Focal high-intensity focused ultrasound targeted hemiablation for unilateral prostate cancer: a prospective evaluation of oncologic and functional outcomes. Eur Urol 2016;69:214-220.

22. Ganzer R, Hadaschik B, Pahernik S, Koch D, Baumunk D, Kuru $T$, et al. Prospective multicenter phase II study on focal therapy (hemiablation) of the prostate with high intensity focused ultrasound. J Urol 2018;199:983-989. 